\title{
The Integration of Verbal Humor into EFL Classrooms: The Issues of Appropriateness and Relevance in Focus
}

\author{
Minoo Alemi ${ }^{1}$, Hessameddin Ghanbar ${ }^{2}$, Atefeh Rezanejad ${ }^{3}$ \\ ${ }^{1}$ Islamic Azad University, West Tehran Branch \\ ${ }^{2}$ Islamic Azad University, Fereshtegan International Branch \\ ${ }^{3}$ Allameh Tabataba'i University
}

Correspondence concerning this article should be addressed to Minoo Alemi, Applied Linguistics, Islamic Azad University, West Tehran Branch, Dadman Blv, Derakhti St, Saghafi St, No 16, Terhran, Iran.

E-mail:minooalemi2000@yahoo.com

\begin{abstract}
The present study examined the manifestations of Iranian male and female EFL teachers' use of humor in the classroom environment. To this end, a qualitative study with 30 participants was implemented in two English language institutes in Iran. Equally, 15 male and female EFL teachers were selected by convenience sampling and their classes were audio-recorded and later transcribed for the examination of the types of humor they used and their frequency. Wanzer, Frymier, Wojtaszcyk, and Smith's (2006) method of humor analysis and categorization of appropriateness was exploited for the analysis of the types of humor collected from the participants of the study. The results suggested that the use of humor by male teachers was more frequent than that of female teachers. It was revealed that $57 \%$ of the humor production was by male EFL teachers and $43 \%$ was produced by female EFL teachers. The results revealed that the most frequent humor type in male teachers' classrooms was "funny comments" (27\%), with "teasing students" (3\%) being the least frequent one. In the case of appropriate humor use, similarly, female teachers used "funny comments" (52\%) as the most frequent one, while there was no instance of "providing humorous examples". Considering inappropriate humor use, both male and female teachers used "funny comments" (45\%) as the most frequent type. The findings of the present study can be of use to EFL teachers and suggests the need for workshops and training courses on the integration of humor into EFL classes.
\end{abstract}

Keywords: humor, appropriate humor, inappropriate humor, classroom interaction analysis

\section{Introduction}

The topic of humor and its impact on the performance of language learners has gained considerable attention during the past two decades (Heidari-Shahreza \& Heydari, 2018). According to Heidari-Shahreza (2020), humor and language are both conceptually and practically interrelated and "tongueless humor is usually a helpless one” (p. 81). Humor or language play is believed to alleviate learners' anxiety (Booth-Butterfield \& BoothButterfield, 1991), increase self-confidence and motivation to learn (Gorham \& Christophel, 1992), help learners shape their own identity (Pomerantz \& Bell, 2011), and lead to joyful class atmospheres (Bell, 2012; Carter \& McCarthy, 2004; Cook, 2000; Heidari-Shahreza \& Heydari, 2018; Wagner \& Urios-Aparisi, 2011). As Heidari-Shahreza (2020, p. 79) posits, "humor-integrated language learning (HILL)" is flourishing in the domain of TESOL (Teaching English to Speakers of Other Languages) and different scholars have addressed this issue from different vantage points.

Different types of humor used by teachers have been investigated in terms of appropriate and inappropriate humor (Wanzer \& Frymier, 1999). Additionally, there is a difference between appropriate and inappropriate humor. Appropriate humor leads to higher teacher evaluations, while inappropriate humor and sarcasm lead to lower teacher evaluations and can negatively impact student learning. Basically, humor constructs classroom cohesion, leads to more students' positive interaction, reduces criticism, and removes individual's stress (Banas, Dunbar, Rodriguez, \& Liu, 2011). On the whole, entangling a complex and complicated construct like humor can facilitate teaching, and in particular, interaction in EFL classrooms. Against this backdrop, the present 
study aimed to investigate the frequency and appropriateness of verbal humor used by Iranian non-native English language teachers.

\section{Literature Review}

\section{Humor}

The literature on humor suggests that different scholars have defined the term differently and there is no consensus on the preferred definition. According to Wagner and Urios-Aparisi (2011, p. 400), humor in language classrooms can be defined as "an act performed through linguistic or non-linguistic means by any of the participants (i.e., student(s) or teacher)". Moreover, as Bell (2011) argues, humor is a "specific communicative mode in which something is uttered with the intent to amuse" (p. 238). Attardo and Raskin (1991) posit that humor is instantiated by verbal jokes. Moreover, Wanzer, et al., (2006) categorized appropriate humor in the classroom as: (a) related humor, (b) humor unrelated to course material, (c) self-disparaging humor, and (d) unintentional humor. Although various definitions have been proposed with regard to the concept of humor, a leading similar observed feature remains to be a matter of incongruity, which finally leads to some joyful moments (Martin, 2007). In the same vein, Schmidt and Williams (2001) believed that incongruity in teaching materials can lead to "sustained attention and subsequent elaborative processes" (p. 311).

However, apart from the establishment of fun and amusement, other potential advantages of humor have been noticed in the educational realm (Berk, 2000; Heidari-Shahreza, 2018; Lovorn \& Holaway, 2015; Mantooth, 2010; Wanzer \& Frymier, 1999; Wanzer, Frymier, \& Irwin, 2010). For instance, it has been argued (Garner, 2006; Wanzer, Frymier, \& Irwin, 2010) that humor can improve and develop the learning outcome. According to Gönülal (2018), humor is regarded as a useful tool in developing a positive classroom atmosphere and bringing more fun into the learning context. Berk (2000) also reported cases where humor could decrease test anxiety among the learners. There is also a positive connection between teachers' use of humor and academic

achievement for students (Hickman \& Crossland, 2004-2005). It might also be an effective relaxing, comforting, and stress-reducing device that can enhance the students' interest and enjoyment (Neuliep, 1991). While humor, as a tool, can be vital for the students' learning, its unbalanced use can be jeopardizing (Azizinezhad \& Hashemi, 2011; Bell, 2009). Several empirical studies (e.g., Deneire, 1995; Schmitz, 2002; Wagner \& UriosAparisi, 2011) have lent support to the advantages and ease that humor can bring to the classroom. According to Schmitz (2002), the appropriate use of humor in the classroom can lead to giving students ease, getting students' attention, and having a less formal classroom.

\section{Gender and Humor}

Humor has many functions and it may be viewed differently in various social contexts. Meanwhile, the important role of humor in bringing together people of different genders cannot be denied. In this regard, many previous studies have confirmed the leading role of gender in humor and its various production forms (e.g. Kazarian \& Martin, 2006; Martin, Puhlik-Doris, Larsen, Gray, \& Weir, 2003; Wu, Lin, \& Chen, 2016; Yip \& Martin, 2006).

The results of the research done by Yip and Martin (2006) further proved this gender difference and indicated that men use more aggressive humor than females. Wu, Lin, and Chen (2016) also asserted that males prefer aggressive humor in different styles; whereas females show more empathy in the understanding or production of humor. This fact is further confirmed by Christov-Moore, Simpson, Coudé, Grigaityte, Iacoboni, \& Ferrari, (2014) who also argued that women generally show more empathy in every social interaction and context.

In the same vein, the results of self-reported questionnaires in the study by Chaplin and Aldao (2013) further demonstrated that females are generally more willing to show empathy in social interactions. Hampes (2010) also stated that there is a direct relationship between humor and empathy. Similarly, according to Wu, Lin, and Chen (2016) there is a correlation between empathy and the types of humor presented by people. To put it differently, people with more empathy show more understanding toward other people's feelings and are less likely to hurt their feelings, and accordingly they use less aggressive humor. 


\title{
Culture and Humor
}

Although humor is a universal concept and observed around the world, it varies based on unique cultural settings. According to Chen and Martin (2007), people from East and West differ in their attitudes and views toward humor and how they use it. As humor is tightly linked to the mental and emotional well-being and status of people, it is necessary to figure out how humor can influence people and their perceptions toward the issue (Chen \& Martin, 2007; Jiang, Li, \& Hou, 2019; Martin, 2001; Martin \& Ford, 2018).

This is more significant bearing in mind that there are controversial findings on the topic (Chen \& Martin, 2007; Hiranandani \&Yue, 2014; Kazarian \& Martin, 2004). For instance, it is believed that Westerners accept humor more freely (Lefcourt, 2001; Martin \& Ford, 2018), whereas Easterners are afraid of endangering their social status be accepting humor (Rudowicz \& Yue, 2002; Yue, 2011). In this regard, Apte (1985) argues that:

\begin{abstract}
Humor is ubiquitous in American society and nothing escapes from becoming its target. Humor in its numerous techniques and forms is directed at the population through all conceivable channels - newsprint, magazines, books, visual and plastic arts, comedy performances, and amateur joke-telling contests, as well as many types of artifacts such as T-shirts, watches, bumper stickers, greeting cards, sculptures, toys, and so forth (p. 30).
\end{abstract}

Along the same lines, Mireault and Reddy (2016) also believe that contextual factors can greatly affect the understandability of humor. In fact, they emphasize "the context of humorous events does not generally refer to a specific physical setting, but instead is an emotional and social context with a dynamic ebb and flow" (p. 58) which can be either internal or external.

\section{Previous Research on Humor in Classrooms}

The topic of humor is a delicate topic to be discussed and accordingly different teachers of different experiences and educational backgrounds have viewed HILL and its benefits from different perspectives (Bell, 2011; Davies, 2015; Heidari-Shahreza, 2018). In one study, Sullivan (2000) explored a Vietnamese EFL teacher's use of humor in the language class, with an eye on the two techniques of storytelling and wordplay (e.g. repetition \& puns) for over two months. The findings indicated that the impulsive occurrences of these two techniques could lead to some humorous atmospheres that later could facilitate the learners' motivation and willingness to engage actively in the class activities. Sterling and Loewen's (2015) observational research study investigated L2 Spanish classroom interactions and instances of teacher-initiated humor with a focus on the linguistic content. The data concerning the playful language-related episodes were collected through audio and video recordings. The results indicated that $6 \%$ of class interactions or $0.5 \%$ of total class time was devoted to humor and playful language.

Olajoke (2013) conducted a study on learners from a tertiary institute in Nigeria. Having controlled for gender in the research, he concluded that humor plays an important role in class activities and that the enhancement of class interactions and the appropriateness of the use of humor relies upon the students' perception and their provided opinions on the diversity and variety of classroom humor. Students' opinions are very influential regarding the appropriateness of humor use, which provides a kind of guidelines for English teachers to help them avoid using the wrong type of humor in their classrooms. As a result, he pointed out that teachers can find strategies to adjust their behaviors and use of humor in the classroom.

Later, in an ethnographic study, Petraki and Pham Nguyen (2016) explored thirty Vietnamese university teachers' perceptions, practices, and preferences with regard to the role of humor and humor types in English as a Foreign Language (EFL) teaching. The utilized instruments included observations, field notes, class video recordings, and interviews. The results showed that all of the teachers either favored or used humor in their language classes. They mainly used humorous comments, jokes, and funny stories to enliven the class atmosphere. In addition, Heidari-Shahreza (2018a) used a cross-sectional analysis of verbal humor and language play instigated by teachers in English as a foreign language (EFL) contexts among Iranian language teachers. The results of the study proved the use of several micro-level verbal humor techniques. The researcher found that puns, allusion, and irony were the three most used techniques applied by the EFL teachers, respectively. Humor forms, funny comments, visual humor, and physical humors were the three most common 
forms used by teachers when teaching elementary levels. Additionally, in a more recent study, Heidari-Shahreza (2020) explored HILL in detail. He proposed that HILL is composed of two key components, namely humor competence and language competence. "The former is mainly concerned with enhancing learners' knowledge of humor or humor competency training, while the latter is basically aimed at developing learners' language proficiency" (p. 82).

\section{Purpose of the Study}

As Schmitz (2002, p. 96) asserts "there is, without any doubt, a need for research on the use of humor in language classrooms". However, according to Petraki and Nguyen (2016), there is a paucity of research on humor in language classrooms. Heidari-Shahreza (2020) also calls for more attention to the necessity of more research on teaching with and about humor. Moreover, most of the previous studies on humor in L2 classes have been devoted to the language learners and researcher have paid scant attention to EFL teachers in the field (Forman, 2011; Heidari-Shahreza, 2018). Along the same lines, Petraki and Nguyen (2016) point out that EFL teachers need to consider the relevance or appropriateness of the humor used in classrooms and more specifically in different language contexts (Schmitz, 2002). Also, to the best of the researchers' knowledge, no other study has investigated the impact of teacher gender on the application of humor in English language classrooms. Therefore, to contribute to the scant literature on language teacher humor in an EFL context, the present study set out to examine the frequency and appropriateness of humor and language play of 30 male and female Iranian EFL teachers. To this end, the following research questions were put forward:

1. What are the frequency and manifestations of appropriate humor in male Iranian EFL teacher talk?

2. What are the frequency and manifestations of inappropriate humor in male Iranian EFL teacher talk?

3. What are the frequency and manifestations of appropriate humor in female Iranian EFL teacher talk?

4. What are the frequency and manifestations of inappropriate humor in female Iranian EFL teacher talk?

5. Is there any significant difference between male and female teachers in terms of the number of appropriate, inappropriate, and total instances of humor?

\section{Materials and Methods}

\section{Participants}

A total of thirty Iranian non-native English language teachers (equally divided into males and females) with an average age of 26 took part in this study. These teachers taught English in different language institutes in Tehran and on average had seven years of teaching experience. More detailed information on the participants is depicted below in Table 1. As illustrated, the majority of the teachers, $40 \%$, were from the TEFL (Teaching English as a Foreign Language) field of study. The majority of the participants (37\%) had a master's degree. The participants' first language was Persian and all of them were under 30 years of age. In addition, although the classes were held in English, there were some instances where the teachers used the learners' first language, Persian, for different purposes, such as clarifying the meaning of unknown words or even for fun.

Table 1

Descriptive statistics for the participants of the study

\begin{tabular}{|c|c|c|c|}
\hline Variables & Categories & Frequency & Percentage \\
\hline \multirow{5}{*}{ Major } & TEFL & 12 & $40 \%$ \\
\hline & Literature & 2 & $7 \%$ \\
\hline & Translation & 1 & $3 \%$ \\
\hline & Linguistics & 1 & $3 \%$ \\
\hline & Non-English & 4 & $14 \%$ \\
\hline
\end{tabular}




\begin{tabular}{|c|c|c|c|}
\hline Variables & Categories & Frequency & Percentage \\
\hline \multirow{3}{*}{ Degree } & B.A. & 8 & $27 \%$ \\
\hline & M.A. & 11 & $37 \%$ \\
\hline & Ph.D. & 1 & $3 \%$ \\
\hline \multirow{2}{*}{ Gender } & Male & 15 & $50 \%$ \\
\hline & Female & 15 & $50 \%$ \\
\hline \multirow{2}{*}{ Years of teaching experience } & $1-5$ years & 9 & $30 \%$ \\
\hline & $6+$ & 11 & $70 \%$ \\
\hline
\end{tabular}

\section{Instruments}

Non-participant observation was used in order to address the research questions of this study. Thus, a recording device was given to each teacher to record the intended session. This was done to avoid the observer effect, which could affect the participants' normal teaching style (Bogdan \& Biklen, 2007; Petraki, \& Nguyen, 2016; Vanderstoep \& Johnston, 2009). All of the teachers provided 90 minutes of audio-recorded data including class interactions and discourse. Occurrences of humor were analyzed in the transcribed texts produced from the class conversations.

\section{Data Collection Procedure}

Having employed a case study, the data were collected from the two institutes, in which 15 male and 15 female teachers had been selected through random sampling. It should be noted that there was no significant difference between the two institutes in terms of the teachers, students, and the books taught. The classes were 90-minutes each and the core approach was communicative language teaching. One session from each teacher's class was recorded via a non-observant method, which is without the presence of the researcher. With the provided recorder, the teachers recorded a complete session of their classes.

\section{Data Analysis}

All 30 audio classes (45 hours of audio-recorded data) were precisely transcribed. Then, the conversations were analyzed from a broader omniscient point of view considering both the conversations and contexts. The overall analysis of the data was based on the coding scheme, borrowed from Frymier, Wanzer, and Wojtaszczyk (2008), which was selected as the main framework of the study (See the Appendix). The coding scheme included the categorization of various types of humor (funny comments, providing jokes, providing humorous examples, making stories, teacher performance, creative language, teasing students, and critical humor), their appropriateness (appropriate or inappropriate), and their relatedness to the content of the study (related or unrelated).

Moreover, based on the classification scheme developed by Wanzer et al. (2006), the humor instances were categorized into their functional categories. The humor types were pinpointed and their frequencies were counted to gain an understanding of the exact times when specific humorous features happened. In addition, through the comparison of the responses and the verbal feedback available from the learners, the researchers were able to understand the extent of each humor's appropriateness. Finally, it should be said that 30\% of the recordings (12 recorded classes comprised of six male teachers and six female teachers) were re-coded by an expert whose expertise was on classroom discourse and two-way random interclass correlations were used for inter-rater reliability.

\section{Results}

\section{RQ1: What are the Frequency and Manifestations of Appropriate Humor in Male Iranian Efl Teacher Talk?}

This question inquired about the number of appropriate instances where male teachers used humor in the classroom. Table 2 clearly illustrates appropriate instances plus the total instances of humor used with regard to the male teachers. As can be seen in Table 2, the total number of appropriate instances of humor was 69 . Furthermore, the 
percentage of appropriate instances of humor produced by male teachers was $58 \%(n=40)$ of the total numbers of appropriate instances of humor produced by all of the teachers. Of the total instances of humor used by male teachers $(\mathrm{n}=49), 82 \%$ were appropriate to the context. Inter-rater reliability was also assessed using a two-way random average measure intra-class correlation coefficient, which was .92 and indicates excellent reliability.

Table 2

Humor instances across gender and type

\begin{tabular}{lccc}
\hline & Appropriate & Inappropriate & Total \\
\hline Male & $40(58 \%)$ & $9(53 \%)$ & $49(57 \%)$ \\
Female & $29(42 \%)$ & $8(47 \%)$ & $37(43 \%)$ \\
Total & $69(100 \%)$ & $17(100 \%)$ & $86(100 \%)$ \\
\hline
\end{tabular}

Based on the data, the mostly-used categories of humor for male teachers were funny comments, creative language, and teacher performance. The most important category of appropriately-used humor was "funny comments". Considering the instances of appropriate humor from male teachers $(n=40), 11$ instances were funny comments amounted were $27 \%$. Of these, $91 \%$ were related to the context and the rest (9\%) was unrelated. The second-most frequent humor type was creative language which occurred nine times (22\%) in male utterances appropriately, with $77.7 \%$ of the instances related and $23.3 \%$ unrelated to the classroom. Teacher performance occurred five times (12\%), among them $80 \%$ were related and $20 \%$ were unrelated. Providing jokes occurred five times (13\%), of which $60 \%$ were related and $40 \%$ were unrelated. Critical humor was noted four times (10\%), all of which were related; making stories three times (8\%), all of which were related; provided examples two times (5\%), 50\% of which was related and the other half were unrelated; and teasing students happened one time (3\%), all of which were related to the context. An example of an appropriate joke used five times $(13 \%)$ by male teachers is depicted in the excerpt below:

S: $\quad$ Teacher, can we say they are? (Instead of Louis and Jack)

T: If you are very lazy and Shirazi yes! (In everyday jokes, Shirazi people are famous for being very lazy). When we have 'and' you can know that they are plural.

It can be understood that in this example the teacher used humor to teach the concept of plural by the use of and.

\section{RQ2: What are the frequency and manifestations of inappropriate humor in male Iranian EFL teacher talk?}

The second research question deals with the general number of occurrences of inappropriate humor by male teachers. As can be seen in Table 2, the total number of instances of inappropriate humor used by teachers were 17. Furthermore, the percentage of instances of inappropriate humor produced by male teachers was $53 \%$ $(n=9)$ of the total number of inappropriate instances of humors produced by both genders. Also, from that total instances of humor used by male teachers $(n=49), 18 \%$ were considered inappropriate to the context. Inter-rater reliability was assessed in this part of the analysis using a two-way random average-measures intraclass correlation coefficient, which was .87 and indicates good reliability.

According to the data, it was contended that the mostly-used categories considered to be inappropriate humor by male teachers were funny comments $(\mathrm{n}=4, \mathrm{p}=45 \%), 50 \%$ of which were related and the other half were unrelated to the context, and teasing students $(n=2, p=22 \%)$, both of which were related to the context of the classroom. Critical humor occurred only once $(\mathrm{p}=11 \%)$ and was related. Similarly, providing examples and creative language both occurred one time $(p=11 \%)$ each and they were unrelated. There were no instances of teacher performance, making stories, or joke provision. Below is an example of a related example of inappropriate humor uttered by a male teacher:

S: $\quad$ I want to go to park and play with slide.

T: $\quad$ The phrase is "to go on a slide". You want to go on a slide! (with a surprising voice)

S: $\quad$ Yes I want to go to park and go on a slide.

T: $\quad$ You want to go on a slide and you call these two ladies babies?!!!

They should buy chocolate for you kid.

Students laugh. 
As can be seen above, the first funny comment was added after giving feedback on the correct use of the phrase "to go on a slide" and the repetition used resulted in greater exposure to the phrase.

\section{RQ3: What are the frequency and manifestations of appropriate humor in female Iranian EFL teacher talk?}

Following the third research question, the two factors of appropriateness and gender were considering once again. As depicted in Table 2, it can be seen that the total number of appropriate instances of humor produced by female teachers was $42 \%(\mathrm{n}=29)$ of the total number of appropriate instances produced by both genders. Likewise, it should be mentioned that from the total number of instances used by female teachers $(n=37), 29$ of them $(78 \%)$ were appropriate to the context. Inter-rater reliability was calculated by means of a two-way random averagemeasures intraclass correlation coefficient, which proved to be .95 and indicates excellent reliability.

It was also found that the most-used categories for appropriate humor by female teachers were funny comments, providing jokes, teacher performance, and creative language. The most important category of appropriately-used humor was funny comments, which occurred 15 times ( $\mathrm{p}=52 \%$ ), and among them 80\% were related and $20 \%$ were unrelated. The second significant humor type was providing jokes, which occurred four times ( $p=14 \%), 75 \%$ of which were related and $25 \%$ were unrelated. Teacher performance was observed three times (10\%), $66.6 \%$ of which were related and $33.4 \%$ were unrelated. Creative language occurred three times $(\mathrm{p}=10 \%), 66.6 \%$ related and $33.4 \%$ unrelated. Critical humor occurred two times $(\mathrm{p}=7 \%), 50 \%$ related and $50 \%$ unrelated. Making stories happened once $(p=3 \%)$ and it was related. Finally, providing examples was not observed at all and teasing students was seen only one time $(\mathrm{p}=4 \%)$ and it was related. To provide an example, the excerpt below manifests a type of unrelated appropriate creative language that was used by a female teacher.
T: And one thing about your phones... and if the authorities know, they will kill me... you can use it as a dictionary... Students laugh
T: $\quad$ But don't use it for checking Instagram, telegram or me and the class, spontaneously (كىومى ،سالك و نم) Students laugh.

As can be seen, a concept from the first language (i.e.,., من و كلاس، بيكوبيى a common situation among Iranian people when at the moment that something interesting is happening, they try to take a picture of that event or with a specific person and say: me and the -----, spontaneously or just now ) was used in the second language, which actually may not be popular or used a lot in the L2. However, it was appropriately used to convey meaning.

\section{RQ4: What are the frequency and manifestations of inappropriate humor in female Iranian EFL teacher talk?}

The last research question deals with the frequency and manifestations of inappropriate humor by female teachers. As shown in Table 2, it can be said that the total instances of inappropriate humor produced by female teachers was $47 \%(n=8)$ of the total instances of inappropriate humor produced by all teachers. Likewise, it should be mentioned that from that total instances of humor used by female teachers $(n=37), 22 \%$ were inappropriate to the context. Additionally, inter-rater reliability was estimated in this part of the study through a two-way random average-measures intra-class correlation coefficient, which was .82 and indicates good reliability.

The data showed that using funny comments was the mostly-used category resulting in inappropriate humor by the female teachers. With regard to female teacher inappropriate humor, four instances were funny comments $(\mathrm{p}=45 \%)$, of which $50 \%$ were related and $50 \%$ were unrelated. The second-most prevalent humor type was joke provision, which occurred twice $(p=22 \%)$, and both of which were related to the context of the classroom. Teasing students occurred once $(p=11 \%)$ and it was unrelated. Example provision was observed one time $(\mathrm{p}=11 \%)$ in an unrelated way as a realization of inappropriate female teacher humor use. There were no instances of teacher performance, critical humor, making stories, or creative language as inappropriate usage. Below is an example of unrelated inappropriate humor uttered by a female teacher.

$\mathrm{T}$ : Oh, you have a guitar. Is it yours?

S1: Yes. 
T: I think you have to play for us.

S1: No.

$\mathrm{T}$ : Yesssssss.

S1: I can't play.

T: Why? What is the problem? I promise that we'll close our eyes.

S2: Because she went to class just two sessions.

T: $\quad$ So after two sessions you can make just some noise. It`s ok. We will enjoy it. Please play dalang dalang (which means an unrelated funny noise) for us.

Students laugh.

In this instance, not only was it inappropriate for the students, but it was also unrelated to the context of the lesson as well. It was just a funny comment about something that popped up.

\section{RQ5: Is there any significant difference between male and female teachers in terms of the number of} appropriate, inappropriate, and the total instances of humor?

To answer this research question, three Mann-Whitney U tests (hereafter MWT) were utilized. We used this non-parametric test instead of independent-samples $t$ tests, a parametric test, given that the distributional assumption of normality, the most important statistical assumption of independent-samples $t$ tests, was not satisfied in any of the distributions except one (see Table 3 for the results of two tests of normality, KolmogorovSmirnov test and Shapiro-Wilk test).

Table 3

Tests of normality

\begin{tabular}{llcccccc}
\hline \multirow{2}{*}{ Humor } & & \multicolumn{3}{c}{$\begin{array}{c}\text { Kolmogorov- } \\
\text { Smirnov }\end{array}$} & \multicolumn{3}{c}{ Shapiro-Wilk } \\
\cline { 3 - 8 } & & Value & df & Sig. & Value & df & Sig. \\
\cline { 3 - 8 } Appropriate & Male & .31 & 15 & .00 & .81 & 15 & .00 \\
& Female & .33 & 15 & .00 & .82 & 15 & .01 \\
\hline Inappropriate & Male & .33 & 15 & .00 & .76 & 15 & .00 \\
& Female & .33 & 15 & .00 & .74 & 15 & .00 \\
\hline \multirow{2}{*}{ Total } & Male & .23 & 15 & .03 & .83 & 15 & .01 \\
& Female & .18 & 15 & .20 & .91 & 15 & .13 \\
\hline
\end{tabular}

As depicted in Table 4, The first MWT test showed that there were no significant differences between male ( $M d n=2, M=2.66)$ and female ( $M d n=2, M=1.93)$ teachers with regard to the number of instances of appropriate humor, $\mathrm{U}=98.5, \mathrm{z}=-.62, \mathrm{p}=.56$. The second MWT also revealed no significant differences between male ( $\mathrm{Mdn}=0, \mathrm{M}=.6$ ) and female $(\mathrm{Mdn}=0, \mathrm{M}=.53$ ) teachers with regard to the number of instances of inappropriate humor, $\mathrm{U}=109, \mathrm{z}=-.16, \mathrm{p}=.90$. Ultimately, the third MWT also illustrated that there were no significant differences between male ( $M d n=2, M=3.26$ ) and female ( $M d n=2, M=2.46$.) teachers with regard to the total instances of humor, $\mathrm{U}=103, \mathrm{z}=-.40, \mathrm{p}=.71$.

Table 4

Descriptive statistics of humor instances across type and gender

\begin{tabular}{lllcccc}
\hline \multicolumn{1}{c}{ Humor } & \multicolumn{1}{c}{ Gender } & N & Mean Rank & Sum of Ranks & Mean & Median \\
\hline Appropriate & Male & 15 & 16.43 & 246.50 & 2.66 & 2 \\
& Female & 15 & 14.57 & 218.50 & 1.93 & 2 \\
\hline \multirow{2}{*}{ Inappropriate } & Male & 15 & 15.73 & 236.00 & 0.6 & 0 \\
& Female & 15 & 15.27 & 229.00 & 0.53 & 0 \\
\hline \multirow{2}{*}{ Total } & Male & 15 & 16.13 & 242.00 & 3.26 & 2 \\
& Female & 15 & 14.87 & 223.00 & 2.46 & 2 \\
\hline
\end{tabular}




\section{Discussion}

The issue of humor and its appropriateness in the EFL context has remained understudied, despite its dramatic impact on the process of teaching and learning a second language. The present research was conducted with the participation of multiple teachers in a foreign language context in order to illustrate the various types of humor used in EFL classrooms with regard to gender. The results showed interesting facts with regard to the appropriateness of humor used by male and female Iranian EFL teachers.

In terms of the first research question, the results revealed that the use of appropriate instances was nearly four times greater than inappropriate ones. From among the appropriate humor examples, male teachers used 40 instances of appropriate humor, which were mainly focused on funny comments, creative language, and teacher performance. The results of the study supported the fact that funny comments were the main tool of humor for male teachers, which is in line with other previous studies (e.g., HeidariShahreza, 2018a). Male teachers performed better using different varieties of humor types. This can be justified bearing in mind that in Iranian Persian culture, men are free and less likely to be judged by their audience. Furthermore, they are usually the starters of humor in conversations, even in their own language and culture; therefore, they tend to be good humor initiators. However, this result runs counter to a number of studies (e.g., Abdullah \& Akhter, 2015; Garner, 2006), which showed that half of the instances of humor used by the male teachers were appropriate. To put it another way, in the present study less than one-fourth of the humor used by the male teachers was considered inappropriate. It may be contended that male teachers felt free to use these types of humor. This finding goes in tandem with Yip and Martin (2006) and $\mathrm{Wu}$, Lin, and Chen (2016) who also asserted that men use more aggressive and inappropriate humor than women.

With regard to the second research question, it was revealed that the male teachers did not have any inappropriate instances of humor use in categories such as "teacher performance", "joke provision", and "story provision". This suggests that, although the use of these types of humor might be less frequent, they were perfectly used as a means of humor provision without any inappropriateness. This finding is in consonance with that of Heidari-Shahreza (2018b), who found that cases of relevant humor outnumbered the irrelevant ones in nearly all observed classrooms. Moreover, the most inappropriate humor type by males was funny comments. One reason that might justify this occurrence is the fact that the frequency of use brought about the frequency of inappropriate use. Therefore, it was perceived that funny comments were actually positive humor types implemented by male teachers but the reason for inappropriate occurrences was that they were being used more than the other types of humor. Other types of humor only had one or two inappropriate instances. By contrast, with regard to the types of inappropriate humor observed from the male teachers, the current study is incompatible with some previous studies (e.g., Abdullah \& Akhter, 2015; Garner, 2006; Wanzer, Frymier, Wojtaszczyk, \& Smith, 2006), who found that inappropriate humor consisted of the teachers sarcastically and humorously talking about sex, race, religion, or sexual orientation.

Regarding the third research question, female teachers also used "funny comments" as their main category of humor provision, to the extent that the difference between their productions was eye-catching considering the paucity of their second and third frequent types of humor. It can be contended that funny comments played an influential role when considering Iranian EFL teachers' humor production, especially in the case of female teachers. It appears that using funny comments is the dominant form of humor provision in Iranian EFL teachers' mother tongue, regardless of their gender. Another significant factor in the practice of funny comments was the difference between male and female teachers. As the results of the current study revealed, female teachers had greater tendencies toward using funny comments as their main tool of humor provision. The examples provided by female teachers were greater in number in comparison with the male teachers. This finding can be justified as a response to the boundaries and limitations faced by female Iranian Muslim EFL teachers. It seems that they preferred to use funny comments as a safer expression of humor provision. This may remind us of the cross-cultural manifestations of humor. It is argued that people around the world (e.g. Westerners and Easterners) act differently in the production and perception of humor (Yue, Jiang, Lu, \& Hiranandani, 2016). For instance, just like Iranian women, Chinese women are also encouraged to laugh quietly (in comparison to men) and in some cases even cover their mouths when laughing (Lin, 1934). 
Another important source of humor production was "creative language" for male teachers. However, considering female teachers, "provision of jokes" was a more frequent form of humor provision in comparison with male teachers. In addition, it was found that most of the humor types used by male teachers were related to the context of the study and the teaching materials. In comparison, female teachers had more unrelated humor, although both male and female teachers used related humor more than the unrelated ones. As mentioned earlier, divergence could be seen in the second most frequently observed humor category. Although, male teachers had a tendency toward using creative language, the usage of jokes seemed to be more consistent with female teachers. However, it was shown that instances of creative language for male teachers were nearly as high as the first one, funny comments. Nine instances of creative language were used by male teachers, which were as frequent as funny comments. On the other hand, female teachers only used jokes four times, which was not comparable with their 15 instances of funny comments. Therefore, a simple but significant conclusion can be made, which is the fact that the usage of funny comments was the main tool of humor provision for females. A thorough analysis and comparison of the current study's results with the related literature on the appropriateness of female EFL teachers' humor indicates that the Iranian female teachers lacked variety in their humor production. Funny comments were basically the only tool of humor production used by female teachers in the present study, which is caused by caused by the insecurity that other humor types may bring to the teaching context. However, Petraki and Nguyen (2016) found that "media/ external objects", "jokes", "examples", and "stories" were among the most frequent methods of humor provision among female teachers.

With regard to the fourth research question on inappropriate humor use, the female teachers in the present research were different from teachers in previous studies. Usually, female inappropriate instances of humor have been proved to be targeting one learner based on a variety of reasons. Actually, disparaging humor was used in eighty percent of the occurrence of such inappropriate instances. By and large, some of the findings in the literature were related to the comparison of the performances and productions of humor from both male and female teachers and the extent of appropriateness of the categories. For instance, a comparison of the relatedness of appropriate humor use was emphasized in Alatalo and Poutiainen's (2016) study. Comparable to our study, their study's results proved the efficiency of the use of related humor in the educational context as a motivational technique used by EFL teachers. In another study, Petraki and Nguyen (2016) reported more uses of humor by female teachers; this is not in harmony with the results of the present study, which indicated more frequent usage of humor by male teachers, apparently due to their freedom of humor initiation. Moreover, along with the findings of the present study, the main tool for humor presentation in their study was funny comments, which may have arisen from the adjacency of cultural factors. Additionally, another factor is the presentation of linguistic elements in the case of puns, allusion, and irony. These can be investigated in the present study considering the presence of linguistic elements according to Wanzer et al.'s (2006) categorization, which had been implemented in the forms of providing jokes, providing examples, and teasing students. Finally, the relevance of the present findings can be pinpointed in the study by Heidari-Shahreza (2018) whose results showed that funny comments were the most frequent type of humor used by teachers.

Finally, regarding the last research question, it was observed that male and female teachers did not show any significant differences in the use of humor in English language classrooms. Although, the male and female teachers were varied in their use of appropriate and inappropriate humor, this difference was not significant. As Holmes (2006) argues, part of the identity of men and women in the workplace is shaped by their use of humor. In fact, it seems that "humor can provide insights into the gender stereotypes to which participants relate, or even subscribe" (Holmes, 2006, 41). According to Crawford (2003, p. 1427), men and women utilize humor in their speech and "in same-gender and mixed-gender settings as one of the tools of gender construction. Through it and other means, they constitute themselves as masculine men and feminine women". Teachers in the current study also may have used humor differently in various classes with different gender distributions. To put it differently, language teachers may use different types of humor when they have a class with male or female students of different age levels or backgrounds. Our results in this study are in line with Abel (1998) who reported no significant difference between the use of humor by males and females in general. Some other researchers however (e.g., Johnson, 1991; Rim, 1988) found differences between males and females in terms of their perceptions and attitudes toward humor. As mentioned previously, no specific study could be pinpointed focusing on the male and female English language teachers' use of humor in the class and their variations. 


\section{Conclusion}

The main objective of the present study was to investigate the appropriateness and relevance of verbal humor among Iranian EFL language teachers. The data were collected through non-observant class observations of thirty male and female EFL teachers. The results observed the frequency of different instances of humor used by male and female teachers and indicated that funny comments were the main type of humor used in Iranian EFL classrooms. Furthermore, male teachers were observed to use more humor more often in comparison with female teachers. In addition, from the 58 instances produced by male teachers, nine of them were inappropriate to the classroom environment. However, from the 40 instances observed by female teachers, eight of them were deemed inappropriate, which was a higher percentage than their male counterparts. Generally, with regard to the overall findings of the study, the role of religion and culture cannot be denied. The male and female teachers in the current study came from an Islamic Iranian cultural background. Undoubtedly, this background could have an effect on the teachers' attitudes and inclinations toward the use of different forms of humor.

The results of our study have a number of pedagogical implications. First and foremost, we think that studies of this kind can raise the awareness of language teachers toward different pedagogical issues. This study brings to the fore the significance of humor and the prevalence of its various types among male and female EFL teachers in language classrooms. It needs to be noted that there are numerous positive points for using humor in the class (e.g. increased learner motivation and lower anxiety levels) and we hope this paper could bring the general significance of humor into the limelight. Moreover, current and prospective EFL teachers, whether in Iran or around the world, can benefit from our findings with regard to the different types of humor used by language teachers. We believe this can raise awareness and make teachers more aware of the significant role of humor in language learning and the learners' success. This would lead to teachers who consider the probable advantages of humor in their classrooms and try to come up with practical techniques to enliven the classroom atmosphere, increase learner motivation and self-confidence, diminish their anxiety, and increase their willingness to communicate. Finally, the present study's results emphasize the necessity of training and education for EFL teachers on the integration of humor into EFL classrooms. The results indicated that Iranian EFL teachers were not totally aware of the different types of humor, their appropriateness in different contexts, and their relevant use in language classes. That is to say, teachers need to be educated on how to practically use different kinds of humor in different situations in EFL classes. This further calls for more attention to the content of teacher education courses. Teacher educators need to assist teachers who are not confident enough in using humor in language classes through conducting workshops on the proper integration of humor into the classroom context.

It needs to be acknowledged that just like any research study, this study had some limitations that may affect the generalizability of the findings. We investigated the use of verbal humor produced by thirty Iranian EFL teachers through observation. Further studies may explore the topic more meticulously through a diversity of research instruments (e.g. questionnaires \& interviews) and with a larger number of participants. Moreover, interested researchers may also investigate teachers' attitudes toward different types of humor and in different educational contexts namely, schools, private institutes, and universities. Also, to shed more light on the use of humor in language classrooms, it seems necessary to investigate language learners' views with regard to humor and its different types along with how they respond to humor initiated by teachers. Finally, one remaining question is whether the various forms of humor can have any impact on the acquisition of a second language among learners of different age levels and cultures in different contexts.

\section{Conflict of interests}

The authors declare that they have no conflict of interest.

\section{References}

Abdullah, S., \& Akhter, J. (2015). Uses of humour in an English language class. International Journal of Humanities and Cultural Studies, 2(2), 16-21.

Abel, M. H. (1998). Interaction of humor and gender in moderating relationships between stress and outcomes. The Journal of Psychology, 132(3), 267-276. 
Apte, M. L. (1985). Humor and laughter: An anthropological approach. Cornell University Press.

Attardo, S. (1994). Linguistic theories of humor. Mouton de Gruyter.

Bell, N. D. (2011). Humor scholarship and TESOL: Applying findings and establishing a research agenda. TESOL Quarterly, 45(1), 134-159. https://doi.org/10.5054/tq.2011.240857

Bell, N. (2012). Comparing playful and nonplayful incidental attention to form. Language Learning, 62(1), 236265. https://doi.org/10.1111/j.1467-9922.2011.00630.x

Berk, R. (2000). Does humour in course tests reduce anxiety and improve performance? College Teaching, 48(4), 151-159. https://doi.org/10.1080/87567550009595834

Bogdan, R. C., \& Biklen, S. K. (2007). Qualitative research for education: An introduction to theories and methods (5 $5^{\text {th }}$ ed.). Pearson.

Booth-Butterfield, S., \& Booth-Butterfield, M. (1991). Individual differences in the communication of humorous messages. Southern Communication Journal, 56, 205-218.

Carter, R., \& McCarthy, M. (2004). Talking, creating: Interactional language, creativity, and context. Applied Linguistics, 25(1), 62-88. https://doi.org/10.1093/applin/25.1.62.

Chaplin, T. M., \& Aldao, A. (2013). Gender differences in emotion expression in children: A meta-analytic review. Psychological Bulletin, 139(4), 735-765. https://doi.org/10.1037/a0030737

Christov-Moore, L., Simpson, E. A., Coudé, G., Grigaityte, K., Iacoboni, M., \& Ferrari, P. F. (2014). Empathy: Gender effects in brain and behavior. Neuroscience and Bio Behavioral Reviews, 46, 604-62 7. https://doi. org/10.1016/j.neubiorev.2014.09.001

Cook, G. (2000). Language play, language learning. Oxford University Press.

Chen, G., \& Martin, R. A. (2007). A comparison of humor styles, coping humor, and mental health between Chinese and Canadian university students. Humor: International Journal of Humor Research, 20, 215-234. https://doi.org/10.1515/HUMOR.2007.011

Crawford, M. (2003). Gender and humor in social context. Journal of Pragmatics, 35(9), 1413-1430. https://doi. org/10.1016/S0378-2166(02)00183-2

Davies, C. E. (2015). Humor in intercultural interaction as both content and process in the classroom. Humor: International Journal of Humor Research, 28(3), 375-395. https://doi.org/10.1515/humor-2015-0065

Forman, R. (2011). Humorous language play in a Thai EFL classroom. Applied Linguistics, 32(5), 541-565. https:// doi.org/10.1093/applin/amr022

Garner, R. L. (2006). Humour in pedagogy: How ha-ha can lead aha! College Teaching, 54(1), 177-180. https://doi. org/10.3200/CTCH.54.1.177-180

Gönülal, T. (2018). Investigating the potential of humour in EFL classrooms: An attitudinal study. European Journal of Humour Research, 6(1), 141-161. https://hdl.handle.net/20.500.12432/1211

Gorham, J., \& Christophel, D. M. (1990). The relationship of teachers' use of humor in the classroom to immediacy and student learning. Communication Education, 39, 46-62.

Hampes, W. P. (2010). The relation between humor styles and empathy. Europe's Journal of Psychology, 6(3), 3445. https://doi.org/10.5964/ejop.v6i3.207

Heidari-Shahreza, M. A. (2018a). A cross-sectional analysis of teacher-initiated verbal humor and ludic language play in an English as a foreign language (EFL) context. Cogent Education, 5(1), 1-20. https://doi.org/ 10.1080/2331186X.2018.1430474

Heidari-Shahreza, M. A. (2018b). A proficiency-based analysis of EFL learners' humorous language play. International Journal of Applied Linguistics, 28(3), 406-423. https://doi.org/10.1111/ijal.12212

Heidari-Shahreza, M. A., \& Heydari, S. (2019). Humor-integrated language learning: A teacher's and student's perspective. TESOL Journal, 10(1), 1-4. https://doi.org/10.1002/tesj.376

Heidari-Shahreza, M. A. (2020). Humor-intergrated language learning (HILL): Teaching with and about humor. In J. Rucynski, \& C. Prichard (Eds.), Bridging the humor barrier: Humor competence training in English language teaching (pp. 79-106). Lexington Books, Rowman \& Littlefield Publishers.

Hiranandani, N. A., \& Yue, X.D. (2014). Humour styles, gelotophobia and self-esteem among Chinese and Indian university students. Asian Journal of Social Psychology, 17, 319-324. https://doi.org/ 10.1111/ajsp.12066

Holmes, J. (2006). Sharing a laugh: Pragmatic aspects of humor and gender in the workplace. Journal of Pragmatics, 38(1), 26-50. https://doi.org/10.1016/j.pragma.2005.06.007

Johnson, A. M. (1991). Sex differences in the jokes college students tell. Psychological Reports, 68, 851-854.

Kazarian, S. S., \& Martin, R. A. (2004). Humour styles, personality, and well-being among Lebanese university students. European Journal of Personality, 18, 209-219. https://doi.org/10.1002/per.505.

Kazarian, S. S., \& Martin, R. A. (2006). Humor styles, culture-related personality, well-being, and family adjustment among Armenians in Lebanon. Humor International Journal of Humor Research, 19(4), 405-423. https://doi.org/10.1515/HUMOR.2006.020 
Lefcourt, H. M. (2001). Humor: The psychology of living buoyantly. Kluwer Academic. https://doi.org/10.1007/978$1-4615-4287-2$

Lin, Y. T. (1934). On humor. Analects Fortnightly, 33, 434-438.

Lovorn, M., \& Holaway, C. (2015). Teachers' perceptions of humour as a classroom teaching, interaction, and management tool. European Journal of Humour Research, 3(4), 24-35. http://dx.doi.org/10.7592/ EJHR2015.3.4.lovorn

Mantooth, J. D. (2010). The effects of professor humour on college students' attention and retention [Unpublished doctoral dissertation]. Auburn University.

Martin, R. A. (2001). Humor, laughter, and physical health: Methodological issues and research findings. Psychological bulletin, 127, 504-519. https://doi.org/10.1037/0033-2909.127. 4.504

Martin, R. A. (2007). The psychology of humor: An integrative approach. Cambridge University Press.

Martin, R. A., \& Ford, T. (2018). The psychology of humor: An integrative approach. Elsevier Academic Press.

Martin, R. A., Puhlik-Doris, P., Larsen, G., Gray, J., \& Weir, K. (2003). Individual differences in uses of humor and their relation to psychological well-being: Development of the humor styles questionnaire. Journal of Research in Personality, 37, 48-75. https://doi.org/10.1016/S0092-6566(02)00534-2

Mireault, G. C., \& Reddy, V. (2016). Humor in infants: Developmental and psychological perspectives. Springer.

Morrison, M. K. (2008). Using humor to maximize learning: The links between positive emotions and education. Rowman \& Littlefield Education.

Petraki, E., \& Nguyen, H. (2016). Do Asian EFL teachers use humor in the classroom? A case study of Vietnamese EFL university teachers. System, 61, 98-109. https://doi.org/10.1016/j.system.2016.08.002

Pomerantz, A., \& Bell, N. D. (2011). Humor as safe house in the foreign language classroom. The Modern Language Journal, 95,148-161. https://doi.org/10.1111/j.1540-4781.2011.01274.x

Rim, Y. (1988). Sense of humour and coping styles. Personality and Individual Differences, 9, 559-564. https://doi. org/10.1016/0191-8869(88)90153-5

Rudowicz, E., \& Yue, X. D. (2002). Compatibility of Chinese and creative personalities. Creativity Research Journal, 14, 387-394. https://doi.org/10.1207/S15326934CRJ1434_9

Schmitz, J. B. (2002). Humor as a pedagogical tool in foreign language and translation courses. Humor: International Journal of Humor Research, 15, 89-113. https://doi.org/10.1515/humr.20 02.0 07

Schmidt, S., \& Williams, A. (2001). Memory for humorous cartoons. Memory and Cognition, 29, 305-311. https:// doi.org/10.3758/BF03194924

Sterling, S., \& Loewen, S. (2015). The occurrence of teacher-initiated playful LREs in a Spanish L2 classroom. System, 53, 73-83. https://doi.org/10.1016/j.system.2015.07.002

Sullivan, P. N. (2000). Playfulness as mediation in communicative language teaching in a Vietnamese classroom. In J. P. Lantolf (Ed.), Sociocultural theory and second language learning (pp. 115-131). Oxford University Press.

Tamblyn, D. (2003). Laugh and learn - 95 ways to use humor for more effective teaching and training. Amacom.

Vanderstoep, S. W., \& Johnston, D. D. (2009). Research methods for everyday life: Blending qualitative and quantitative approaches. Jossey-Bass.

Wagner, M. \& Urios-Aparisi, E. (2011). The use of humor in the foreign language classroom: Funny and effective. Humour: International Journal of Humour Research, 24(4), 399-434. https://doi.org/10.1515/humr.2011.024

Wanzer, M., \& Frymier,A. (1999). The relationship between student perceptions of instructor humor and students' report of learning. Communicative Education, 48, 48-62. https://doi.org/10.1080/03634529909379152

Wanzer, M., Frymier, A., Wojtaszczyk, A., \& Smith, T. (2006). Appropriate and inappropriate uses of humor by instructors. Communication Education, 55, 178-196. https://doi.org/10.1080/03634520600566132

Wanzer, B. M., Frymier, A. B., \& Irwin, J. (2010). An explanation of the relationship between instructor humour and student learning: Instructional humour processing theory. Communication Education, 59(1), 1-18. https:// doi.org/10.1080/03634520903367238.

Wu, C. L., Lin, H. Y., \& Chen, H. C. (2016). Gender differences in humour styles of young adolescents: Empathy as a mediator. Personality and Individual Differences, 99, 139-143.

Yip, J. A., \& Martin, R. A. (2006). Sense of humor, emotional intelligence, and social competence. Journal of Research in Personality, 40(6), 1202-1208. https://doi.org/10.1016/j.jrp.2005.08.005

Yue, X. D. (2011). The Chinese ambivalence to humor: Views from undergraduates in Hong Kong and China. Humor: International Journal of Humor Research, 24, 463-480. https://doi.org/10.1515/humr.2011.026.

Yue, X., Jiang, F., Lu, S., \& Hiranandani, N. (2016). To be or not to be humorous? Cross cultural perspectives on humor. Frontiers in Psychology, 7, 1495-1512. https://doi.org/10.3389/fpsyg.2016.01495 


\section{Appendix}

The coding scheme for the categorization of various types of humor (Frymier, Wanzer, \& Wojtaszczyk, 2008):

- Funny comments: use of some humorous words or phrases in order to add some fun to the talk

- Providing jokes: telling some famous jokes about common subjects where both the teachers and the students are aware of

- providing humorous examples: funny and humorous examples of are mentioned of when someone did the funny thing

- making stories: short funny stories are recalled to make someone laugh

- teacher performance: use of some actions by the teacher to make the students laugh, which may include some physical activity

- creative language: includes the creative use of language and use of funny words in humor along with play with words

- teasing students: use of some funny comments relating to the students and their actions to enliven the class atmosphere

- critical humor: a humor which may include harsh or offensive jokes or satire 